\title{
BMJ Open Investigation of the airway management practice of emergency department ward nurses: a nationwide survey in China
}

\author{
Juan Deng, ${ }^{1,2,3}$ Sufang Huang (id , , ${ }^{1,2}$ Dengxiu Zou, ${ }^{1,2,3}$ Weiquan Liu, ${ }^{1,2,3}$ Mei He, ${ }^{1,2,3}$ \\ Jie Xiong, ${ }^{1,2,3}$ Hui Wang ${ }^{1}$
}

To cite: Deng J, Huang S, Zou $\mathrm{D}$, et al. Investigation of the airway management practice of emergency department ward nurses: a nationwide survey in China. BMJ Open 2021;11:e049869. doi:10.1136/ bmjopen-2021-049869

- Prepublication history and additional supplemental material for this paper are available online. To view these files, please visit the journal online (http://dx.doi.org/10.1136/ bmjopen-2021-049869).

Received 03 February 2021 Accepted 22 November 2021

Check for updates

(C) Author(s) (or their employer(s)) 2021. Re-use permitted under CC BY-NC. No commercial re-use. See rights and permissions. Published by BMJ.

${ }^{1}$ Nursing department of Tongji Hospital, Tongji Medical College of Huazhong University of Science and Technology, Wuhan, China

${ }^{2}$ Department of Emergency, Tongji Hospital,Tongji Medical College of Huazhong University of Science and Technology, Wuhan, China

${ }^{3}$ Department of Intensive Care Unit, Tongji Hospital,Tongji Medical College of Huazhong University of Science and Technology, Wuhan, China

Correspondence to Dr Sufang Huang; sfhuang2008@163.com

\section{ABSTRACT}

Objectives To investigate the airway management equipment and clinical practice in emergency department wards in China, and to explore the factors that influenced the nurses' airway management practice.

Design Cross-sectional study.

Setting A nationwide survey covering the seven administrative regions of China (North China, Northeast China, East China, Central China, South China, Southwest China and Northwest China).

Participants The nurses had to be registered nurses who worked in adult emergency department wards of the selected hospitals.

Measures An online survey was designed, piloted and distributed to the members of the Emergency Medicine Committee of the Chinese Nursing Association, and the nurses from the members' hospitals were invited to participate. The questionnaire was used to determine nurses' clinical practice scores of airway management in emergency wards.

Results Finally, we collected 995 valid questionnaires from 31 provinces and 143 districts in China. Among them, $361(36.28 \%)$ nurses responded that their departments used open suction system (OSS) in clinical work, the major barrier for closed suction system (CSS) reported by 630 respondents $(63.32 \%)$ was cost. Significant differences in all three scores were found in age, nursing experience years, technical title, airway management training experience and nursing specialist (all $p<0.05$ ). Correlations were found among airway management attitude, practice of sputum aspiration and practice of ventilator care bundles $(r=0.655, r=0.543$ and $r=0.763$, all $p<0.001)$.

Conclusions Chinese emergency department managers need to identify better methods for assessing equipment availability in OSS. CSS can be a choice when costs, status of the individual patient and severity of disease are comprehensively considered. Emergency department nurses' scores of airway management practice were affected by demographic and job-related characteristics; regular training should be encouraged, and equipment and resources should be guaranteed to improve airway management quality and optimise patient outcomes.

\section{INTRODUCTION}

Airway management is at the core of emergency medicine and can ensure airway patency and save critically ill patients. ${ }^{12}$ Endotracheal

\section{Strengths and limitations of this study}

- Airway management practice in emergency department is associated with several complications and risks that result in multiple factors; this study first investigated the equipment availability of endotracheal suctioning and airway management clinical practice status in emergency department wards in China.

- This study is strengthened by collecting a nationwide sample of Chinese nurses from 143 districts in 31 provinces in 7 administrative regions in China.

- The survey explored the equipment availability and barriers to using OSS and CSS with the potential to provide emergency department wards nationally with a direction for improvement of equipment availability.

- Survey response may have been subject for a selfdesigned questionnaire, and the reliance on participant self-reporting and recall bias.

suctioning and ventilator-associated pneumonia (VAP) prevention are two critical factors in airway management that require high attention. Airway management in these critical parts in emergency departments is associated with several complications and risks that result in multiple factors, such as operator and situational factors related to staff training and expertise, relative urgency, device selection and equipment availability. ${ }^{3}$

Evidence-based practice (EBP) is widely adopted in clinical work to ensure that patients are provided with optimal and consistent care. As critical elements of EBP, well-designed clinical practice guidelines and ventilator care bundles (VCBs) for airway management can provide perfect solutions in airway management for optimising patient outcomes as well as minimising patient risks and complications.

In clinical practice of VCB, VAP remains a worldwide hospital-acquired infection issue ${ }^{2}$ and the VCBs are widely applied into practice and have decreased the incidence of VAP 
in some hospitals. Marini et at examined multifaceted bundle interventions in different multidisciplinary intensive care units (ICUs) and increased compliance with the care bundle from $83 \%$ to $>95 \%$ for more than 1 year, and decreased the incidence of VAP from 4.0 to 0.8 per 1000 patient days. Liu et a $\tilde{p}$ used VCBs to manage VAP in an ICU of a general tertiary hospital in China, and the compliance rate of hand hygiene increased from $71.99 \%$ to $91.97 \%$, the incidence rate of VAP was statistically and significantly lower in the intervention group $(13.70 \%)$ compared with the control group (18.85\%), and the head-of-bed elevation of $30^{\circ}-45^{\circ}$ increased from $62.02 \%$ to $85.96 \%$.

In clinical practice of endotracheal suctioning, compliance of clinical practice seems to be not that optimistic. According to clinical practice guidelines on endotracheal suctioning of mechanically ventilated patients with artificial airways published by the American Association of Respiratory Care (AARC) in $2010^{6}$ and endotracheal suctioning in adults receiving invasive mechanical ventilation published by the Chinese Nursing Association (CNA) in 2021, ${ }^{7}$ endotracheal suctioning should be performed only when secretions are present and not routinely, and the routine use of normal saline instillation before endotracheal suction should not be performed. Finally, closed suction is suggested for adults with high fractional inspired oxygen ( $\mathrm{FiO} 2)$ or positive end expiratory pressure (PEEP) or those at risk of lung derecruitment, haemodynamic instability, respiratory infection (eg, tuberculosis) and multidrug-resistant bacterial infection in the respiratory tract. Guan et al surveyed 21279 nurses working in China who performed airway secretion aspiration in adults with invasive mechanical ventilation, and found $50.19 \%$ nurses chose to perform aspiration on time and on demand, while $17.46 \%$ nurses always or often dropped saline into the airway during sputum aspiration. Leddy and Wilkinson ${ }^{9}$ surveyed 180 healthcare professionals working in the ICUs of six hospitals in Ontario (Canada) and reported the same status quo as that of Guan $e$ al. ${ }^{8}$

Due to the inadequate compliance in airway management clinical practice guidelines and VCBs stated above, we noticed a considerable discrepancy existing between guidelines and nurses' clinical practice without regular intervention and supervision. In Chinese emergency departments, due to the common problem of difficulties in getting medical treatment in China, the emergency departments of some hospitals in China are equipped with emergency ICU wards or resuscitation rooms, which detain many critically ill patients receiving treatment. Timely and effective endotracheal intubation has significantly improved the survival rate of critically ill patients in emergency rescue, but how about the performance of emergency nurses in endotracheal suctioning and the VCBs as two critical parts in airway management? It is currently unclear whether the equipment availability and the strategies described in these guidelines and VCBs are known and correctly followed by nurses in Chinese emergency departments. Therefore, we aimed to investigate the airway management equipment and clinical practice in emergency department wards in China, and to explore the factors that influenced the airway management practice. Improving our understanding of this could help develop strategies for improving airway management conditions and enhancing quality of airway management practice in the future.

\section{METHODOLOGY}

\section{Patient and public involvement}

As this study focused on emergency department wards and nurses, patients or the general public were not involved in the study design.

\section{Study design and participants}

This nationwide study adopted a cross-sectional design using a web-based questionnaire. An online survey was designed and distributed to the members of the Emergency Medicine Committee of the CNA from 1 June to 31 August 2019, via WeChat groups and emails. The content and purpose of the questionnaire were explained to the nurses before answering the questionnaire began. Filling the questionnaire was considered as a de facto consent to participate in the study. All questionnaires were filled anonymously. The anonymity and confidentiality of the participants was ensured in the web-based investigation.

The inclusion criterion was the nurses had to be registered nurses who worked in adult emergency department wards of the selected hospitals. The exclusion criteria were: (1) nurses on long-term (>3 months) sick leave or maternity leave, (2) nurses in training in the emergency departments or interns, (3) nurses who refused to participate in the study, (4) nurses who were in the emergency department but did not take care of patients with invasive mechanical ventilation.

\section{Distribution of the questionnaires}

The questionnaires were distributed to the working group of the Emergency Medicine Committee of the CNA, covering the seven administrative regions of China (North China, Northeast China, East China, Central China, South China, Southwest China and Northwest China). At least six hospitals (provincial and non-provincial, teaching and non-teaching, military and non-military) were selected randomly in the respective administrative areas. The committee member notified the head of the emergency department of the unit chosen randomly in the administrative region of the committee member. All the nurses in the target hospitals' emergency departments and who met the eligibility criteria were proposed to participate.

\section{Data collection}

Data were collected using a self-designed questionnaire named nurses' clinical practice of airway management in emergency wards including 46 items. The questionnaire was developed by the investigators based on an 
extensive review of literature, standard recommendations and protocols. ${ }^{6}{ }^{10-16}$ The survey questions (online supplemental table 1) were then entered into an online survey that was named 'Wen Juan Xing' (Changsha Ranxing Information Technology Co) (https://www.wjx.cn/). The entire questionnaire covered three domains: demographic data, airway management equipment, and airway management attitudes and clinical practice-based questions. The demographic and job-related characteristics included 10 items such as sex, age, years of nursing experience, technical title, administrative post, the highest level of educational degree, city and district of work, the hospital level, training experience in airway management, and being a nursing specialist in airway management or not. The airway management equipment questions contained six items related to equipment availability and technical status; the six items were mainly expressed as true/false statements. The practice-based items consisted of 30 items to assess the levels of nurses' attitude and practice. This section consisted of three parts: (1) questions about airway management attitude (7 items); (2) questions regarding sputum aspiration practice (12 items) and (3) questions about VAP prevention practice (11 items). In the questionnaire, the attitude and practice in airway management of the emergency department nurses were assessed by using options rated based on the statement 'I think I agree with this' with a 5-point Likert scale (1-5): (1) strongly disagree; (2) disagree; (3) more or less; (4) agree and (5) in full agreement. The total Cronbach's $\alpha$ of the subscales named airway management attitudes and clinical practice-based questions was 0.962 , the Cronbach's $\alpha$ of three parts of these subscales were 0.956 , 0.932 and 0.934 , respectively.

The questionnaire was designed by limiting each ID number to fill out the questionnaire once so that only one response per nurse was counted. The ID number was necessary to $\log$ in to the questionnaire web page but was not included in the questionnaire itself.

Qualified questionnaires were defined as all the questionnaire items being complete, without logic errors among answers. Invalid questionnaires were those with a filling time $<3 \mathrm{~min}$, nurses in emergency departments of non-public hospitals answered the questionnaire or there were logic errors (eg, years of experience conflicting with age).

\section{Data analysis}

All questionnaires returned to the authors within 3 months were compiled in a Microsoft Excel file using a double-entry method. Statistical analysis was conducted using SPSS V.13.0. All the data were screened to detect errors before analysis. The airway management attitude score was the total score of seven items of part 1 and the total score was 35 . The sputum aspiration practice score was the total score of 12 items of part 2 and the total score was 60 . The VCBs practice score was the total score of 11 items of part 3 and the total score was 55. The distribution of the variables was examined for normality using the
Shapiro-Wilk and Kolmogorov-Smirnov test. Descriptive and inferential statistics were used to analyse the data. Descriptive statistics included frequency, percentage, median and quartile. The Mann-Whitney $\mathrm{U}$ test and Kruskal-Wallis test were used to determine the relationship between demographic characteristics and airway management attitude and practice scores. The Bonferroni corrected chi-square test was used for further pairwise comparison. The Spearman correlation coefficient test was used to analyse the correlations among airway management attitude, the practice of sputum aspiration and VCBs practice scores. All tests were two tailed, and $p$ values of $<0.05$ were considered statistically significant.

\section{RESULTS}

\section{Characteristics of the participants}

The questionnaire was completed by 1338 emergency department ward nurses, but 334 did not meet the inclusion criteria (eg, answered being from departments other than emergency), and nine questionnaires had obvious logic errors. Finally, 995 valid responses to questionnaires were included. Due to the inability to track the survey distribution, it was not possible to calculate a response rate. However, sampling bias was minimised by ensuring the survey was notified covering the seven administrative regions of China, and at least six different types of hospitals were selected randomly in the respective administrative areas. The enrolled nurses were from 31 provinces and 143 districts in China, with 830, 155, and 10 being from tertiary, secondary, and first-level hospitals, respectively, with the smallest numbers being from the Northeast and Southwest administrative regions.

\section{Airway management equipment and techniques in emergency department wards}

In this study, 361 (36.28\%) nurses responded that their departments used open suction system (OSS) in clinical work, meanwhile $132(13.27 \%)$ used closed suction system (CSS), and 502 (50.45\%) used both OSS and CSS. For those who used OSS or both OSS and CSS $(n=863)$, $767(88.87 \%)$ respondents said that they are checking equipment for proper functioning by suctioning a small amount of sterile saline from the container. Moreover, $462(46.43 \%)$ reported they changed the sterile saline containers every 4 hours, $378(37.99 \%)$ reported once a day, $103(10.35 \%)$ said every shift of work (every 6 hours), $52(5.23 \%)$ said every 12 hours. Only 589 (59.20\%) nurses responded that their departments monitored saline containers and equipment surfaces for contamination. For those using CSS $(n=634), 400(63.09 \%)$ nurses responded that they changed closed suction catheter once a day, $91(14.35 \%)$ responded every 3 days, 78 $(12.30 \%)$ said once a week and $65(10.25 \%)$ responded other replacing frequencies. The barriers to prevalent use of CSS (figure 1) were as follows: 630 (63.32\%) respondents thought materials were expensive and some patients could not afford them, $379(38.09 \%)$ said that 
Patients' mouth and other parts couldn't be suctioned by closed suction catheter
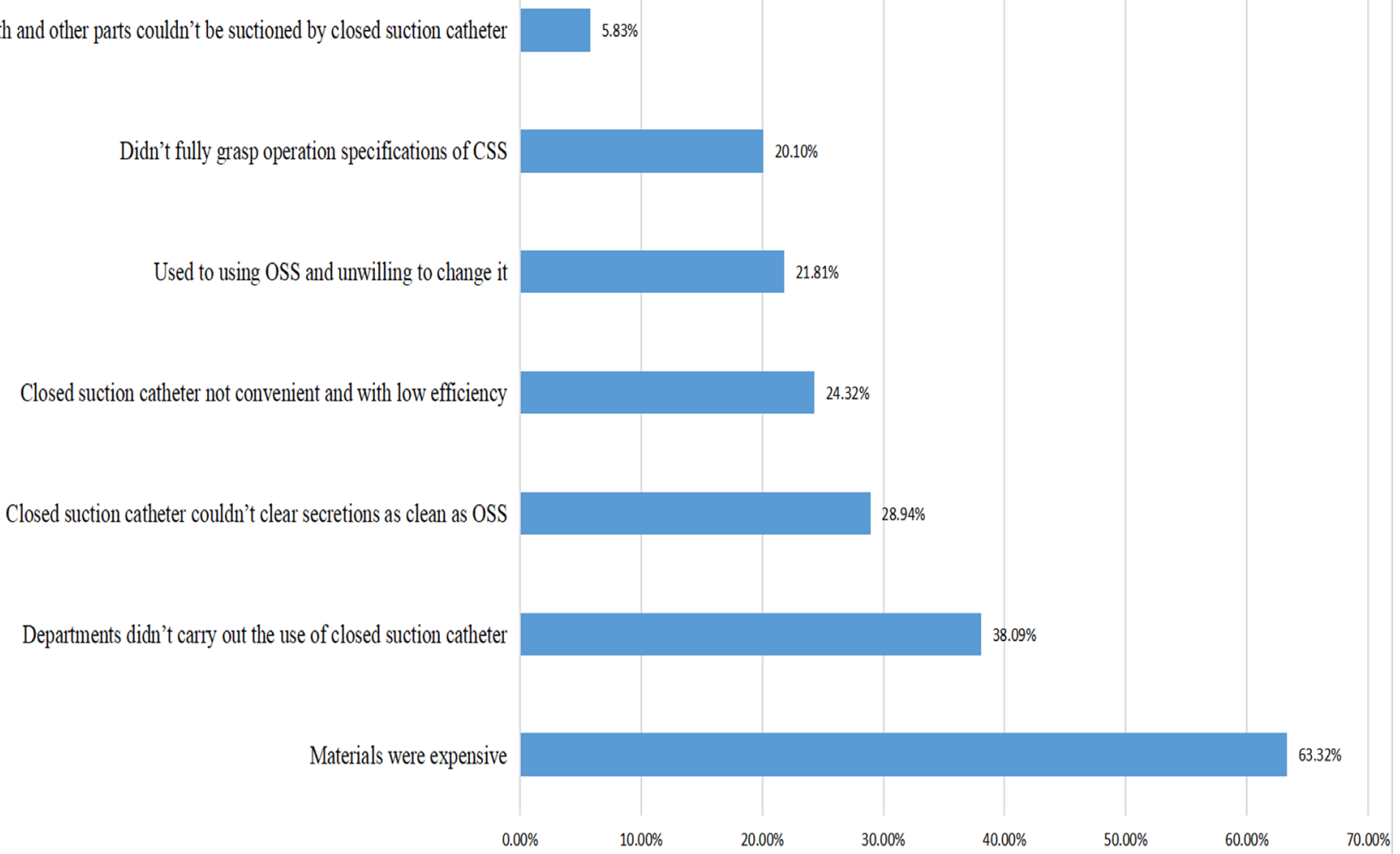

Figure 1 The barriers to the prevalent use of CSS. The 995 respondents reported seven reasons. CSS, closed suction system; OSS, open suction system.

their departments did not carry out the use of a closed suction catheter, 288 (28.94\%) nurses subjectively felt that the closed suction catheter could not suction the airway as clean as the sterile suction catheter, 242 (24.32\%) nursing staff felt that the operation of the closed suction catheter was not convenient and affected work efficiency, $217(21.81 \%)$ were used to using OSS at work and unwilling to change it, $200(20.10 \%)$ nursing staff did not fully grasp the operation specifications of CSS, and $58(5.83 \%)$ said that the patients' mouth and other parts could not be suctioned by a closed suction catheter.

\section{Demographic and job-related characteristics in airway management attitude, practice of sputum aspiration and practice of VCBs}

The emergency department ward nurses' airway management attitude, the sputum suction practice and practice of VCBs median scores were 31, 48 and 44 points, respectively, and the ratios of respondents meeting the median scores were $50.35 \%$ (501 of 995), $79.50 \%$ (791 of 995) and $99.30 \%$ (988 of 995), respectively. The demographic and job-related characteristics are shown in table 1, along with the airway management attitude, practice of sputum suction and practice of VCBs scores.

Female nurses had no significant differences with male nurses in all three scores (all p $>0.05$ ). Nurses aged 41-50 years or over 50 years had higher scores in airway management attitude than those aged $18-20$ years ( $\mathrm{p}=0.026$ and $\mathrm{p}=0.034$, respectively $)$, and nurses aged
$31-40,41-50$, or over 50 years also had higher scores than those aged $21-30$ years $(\mathrm{p}<0.001, \mathrm{p}<0.001$ and $\mathrm{p}=0.020$, respectively). Regarding the practice of sputum aspiration, nurses aged over 50 years had higher scores than those aged $18-20$ years $(\mathrm{p}=0.038)$, and nurses aged $41-50$ years or aged $31-40$ years have higher scores than those aged 21-30 years $(\mathrm{p}<0.001$ and $\mathrm{p}=0.039$, respectively $)$. Nurses aged $31-40,41-50$ or over 50 years had higher scores in the practice of VCBs than those aged 18-20 years $(\mathrm{p}=0.038, \mathrm{p}=0.009$ and $\mathrm{p}=0.003$, respectively). On nursing experience, nurses with 11-20, 21-30 or over 30 years of work experience had higher airway management attitude scores than those who worked less than 1year $(\mathrm{p}=0.006, \mathrm{p}<0.001$ and $\mathrm{p}=0.038$, respectively) or $1-3$ years ( $\mathrm{p}=0.001, \mathrm{p}<0.001$ and $\mathrm{p}=0.023$, respectively), and nurses with 21-30 years of work experience had higher airway management attitude scores than those who worked 4-10 years $(p<0.001)$. Nurses who had worked for 21-30 years or over 30 years had a higher practice of sputum suction than those who worked less than 1 year $(p=0.001$ and $\mathrm{p}=0.038$, respectively), and nurses who had worked for 21-30 years also had better scores in this than those who worked for $2-3$ years or $4-10$ years $(\mathrm{p}=0.009$ and $\mathrm{p}=0.001$, respectively). Nurse-in-charge and co-chief superintendent nurse had higher scores in airway management attitude (both $\mathrm{p}<0.001$ ) and the practice of sputum aspiration $(p<0.001$ and $p=0.006$, respectively) than nurse practitioners, and nurse-in-charge had higher scores in 
Table 1 Nurses' demographic characteristics and scores on airway management attitude, practice of sputum aspiration and practice of VCBs, ranked on a 5-point Likert scale (1-5): (1) strongly disagree; (2) disagree; (3) more or less; (4) agree and (5) in full agreement

\begin{tabular}{|c|c|c|c|}
\hline Subgroup & Airway management attitude & Practice of sputum aspiration & Practice of VCBs \\
\hline \multicolumn{4}{|l|}{ Sex } \\
\hline Male $(n=81)$ & $31(28.00,35.00)$ & $48(43.50,56.50)$ & $44(41.00,50.50)$ \\
\hline \multicolumn{4}{|l|}{ Age (years) } \\
\hline $18-20(n=7)$ & $23(21.00,29.00)$ & $36(36.00,48.00)$ & $33(33.00,44.00)$ \\
\hline $41-50(n=158)$ & $34(28.00,35.00)$ & $50(47.00,57.00)$ & $46(43.00,52.00)$ \\
\hline$\geq 51(n=27)$ & $34(29.00,35.00)$ & $54(47.00,59.00)$ & $47(44.00,54.00)$ \\
\hline \multicolumn{4}{|l|}{ Years of experience } \\
\hline$\leq 1(n=77)$ & $28(26.00,34.50)$ & $48(42.00,53.00)$ & $44(39.50,53.00)$ \\
\hline $21-30(n=145)$ & $34(28.50,35.00)$ & $51(47.50,58.00)$ & $46(43.00,52.00)$ \\
\hline$\geq 31(n=33)$ & $34(28.00,35.00)$ & $52(47.00,58.50)$ & $47(43.00,53.50)$ \\
\hline \multicolumn{4}{|l|}{ Technical title } \\
\hline Nurse practitioner and below $(n=536)$ & $28(28.00,34.00)$ & $48(44.00,54.00)$ & $44(40.00,50.00)$ \\
\hline Nurse-in-charge $(n=314)$ & $33(28.00,35.00)$ & $49(47.00,56.00)$ & $45(42.00,52.00)$ \\
\hline Co-chief superintendent nurse $(n=130)$ & $34(29.00,35.00)$ & $50(47.00,56.25)$ & $46(42.00,51.25)$ \\
\hline Chief superintendent nurse $(n=15)$ & $35(28.00,35.00)$ & $50(47.00,58.00)$ & $45(43.00,52.00)$ \\
\hline \multicolumn{4}{|l|}{ Administrative position } \\
\hline None $(n=692)$ & $29(28.00,34.00)$ & $48(45.00,54.00)$ & $44(41.00,51.00)$ \\
\hline Master's in nursing and above $(n=25)$ & $34(29.00,35.00)$ & $52(47.50,58.50)$ & $47(44.00,54.00)$ \\
\hline \multicolumn{4}{|l|}{ Hospital level } \\
\hline Tertiary $(n=830)$ & $30(28.00,35.00)$ & $48(45.75,55.00)$ & $44(42.00,51.00)$ \\
\hline Second level $(n=155)$ & $31(28.00,35.00)$ & $48(46.00,55.00)$ & $44(40.00,51.00)$ \\
\hline First level $(n=10)$ & $34(29.75,35.00)$ & $50(47.00,60.00)$ & $49(42.75,55.00)$ \\
\hline \multicolumn{4}{|l|}{$\begin{array}{l}\text { Training experience in airway } \\
\text { management }\end{array}$} \\
\hline Yes $(n=851)$ & $31(28.00,35.00)$ & $48(46.00,55.00)$ & $44(42.00,51.00)$ \\
\hline No $(n=144)$ & $28(27.00,34.00)$ & $48(42.25,53.00)$ & $44(38.25,49.00)$ \\
\hline \multicolumn{4}{|c|}{ Nursing specialist in airway management } \\
\hline Yes $(n=334)$ & $33(28.00,35.00)$ & $49(47.00,56.00)$ & $46(43.00,52.00)$ \\
\hline No $(n=661)$ & $29(28.00,35.00)$ & $48(45.00,55.00)$ & $44(41.00,51.00)$ \\
\hline
\end{tabular}

Likert scores have been shown as median (first quartile (25\%), third quartile (75\%)) ( $n=995)$.

Significant differences were found between age, years of experience, technical title, training experience in airway management, and nursing specialist in airway management in all three subscales of the attitude and practice in airway management $(a l l ~ p<0.05)$. In subgroup of sex and hospital level, no significant differences were found in all three subscales of the attitude and practice in airway management (all $p>0.05$ ). In subgroup of administrative position and educational level, significant differences were found in airway management attitude and practice of sputum aspiration scores (all $p<0.05$ ), no significant differences were found in practice of VCBs scores (both $p>0.05$ ).

VCBs, ventilator care bundles. 
practice of VCBs $(p=0.041)$ than nurse practitioners. For administrative positions, head nurses had higher scores in airway management attitude and the practice of sputum aspiration than nurses without administrative positions (both $\mathrm{p}<0.001$ ). On the educational level, those with bachelor's or master's degree in nursing had higher airway management scores than those with vocational school educational level $(\mathrm{p}<0.001$ and $\mathrm{p}=0.007$, respectively). When it came to the hospital level, no significant differences were found in all three scores among different levels of hospitals $(p>0.05)$. Besides, nurses with training experience in airway management or a nursing specialist had better scores in airway management (both $\mathrm{p}<0.001$ ), the practice of sputum aspiration $(\mathrm{p}=0.002$ and $\mathrm{p}=0.001$, respectively) and practice of VCBs $(\mathrm{p}=0.002$ and $\mathrm{p}=0.003$, respectively).

In the practice of sputum aspiration, the three lowest score items were evaluation and auscultating before the suction procedure, utilisation of closed suction for adults with high FiO2 or PEEP, or those at risk of lung derecruitment, haemodynamic instability, respiratory infection (eg, tuberculosis) and multidrug-resistant bacterial infection in the respiratory tract. In the practice of VCBs, performing interrupting continuous sedative infusions, utilisation of subglottic suctioning and measuring the pressure of airbag were three items with the lowest scores.

\section{Correlations among airway management attitude, practice of sputum aspiration and practice of VCBs}

The bivariate correlations among airway management attitude, practice of sputum aspiration and practice of VCBs are shown in table 2. Positive correlations were observed among airway management attitude, practice of sputum aspiration and practice of VCBs (all $\mathrm{p}<0.001$ ). Airway management attitude data correlated with scores on the practice of sputum aspiration $(\mathrm{r}=0.655, \mathrm{p}<0.001)$ and the practice of VCBs $(r=0.543, p<0.001)$. The scores on the practice of sputum aspiration correlated with the scores on the practice of VCBs $(\mathrm{r}=0.763, \mathrm{p}<0.001)$. These results indicated that those who had a better airway management attitude might better perform sputum suction and VCBs in their daily work.

\section{DISCUSSION}

In this study, we identified that in most occasions, emergency department ward nurses used OSS for sputum suction, but the equipment and environment management of sputum aspiration in OSS need further development. For the use of CSS, the major barrier was high cost. Furthermore, nurses' airway management attitude scores were low, the sputum aspiration practice scores and practice of VCBs scores were relatively optimistic. Significant differences were found in airway management attitude and clinical practice among emergency department nurses with different characteristics. Finally, there were positive bivariate correlations among airway management attitude, practice of sputum aspiration and practice of VCBs.

In China, it appears that nurses in emergency wards use OSS more frequently, further work is required for equipment and environment management. There are no standard methods for equipment storage, and we usually apply the clinical experience passed down. Before endotracheal suctioning, a small amount of sterile saline is suctioned to check the negative pressure; after suctioning the secretions, a small amount of saline is suctioned to clean the suction tube. In this procedure, two similarly packaged bottles of $500 \mathrm{~mL}$ normal saline are used and should be stored under sterile conditions; they are usually changed every 4 hours. Once opened, the mouth of the bottle should be disinfected with $75 \%$ ethanol cotton swabs and wrapped with a sterile gauze. ${ }^{17}$ Not performing a timely replacement or good storage would cause a lot of potential hazards for the contamination of the suction catheter and the environment. $\mathrm{Xu}$ et $a l^{17}$ reported two cases of positive bacterial cultures after 4 hours of normal saline use for checking the negative pressure. In this study, $767(88.87 \%)$ respondents admitted to checking the equipment for proper functioning by suctioning a small amount of sterile saline from the container, and only $462(46.43 \%)$ reported they changed the sterile saline containers every 4 hours; only 589 (59.20\%) nurses responded that their departments monitored saline containers and surface of the equipment for contamination. It is well known that the risk of contamination is very high in an open aspiration system when aspirating secretions and body fluids. ${ }^{18}$ Normal saline can be contaminated when checking the equipment for proper functioning, thereby infecting the patients. Emergency department managers should pay more attention to monitoring saline containers and equipment surfaces for contamination, and identify better methods for assessing

Table 2 Airway management practice scores and their correlations ( $n=995, r$ values)

\begin{tabular}{llll}
\hline Variables & Airway management attitude & Practice of sputum aspiration & Practice of VCBs \\
\hline Airway management attitude & 1 & 0.655 & 0.543 \\
Practice of sputum aspiration & 0.655 & 1 & 0.763 \\
Practice of VCBs & 0.543 & 0.763 & 1 \\
\hline
\end{tabular}

Airway management attitude data correlated with scores on the practice of sputum aspiration $(r=0.655, p<0.001)$ and the practice of VCBs $(r=0.543, p<0.001)$. Practice of VCBs correlated with scores on the practice of sputum aspiration $(r=0.763, p<0.001)$.

VCBs, ventilator care bundles. 
equipment availability. Nurses may consider checking the equipment for proper functioning by occluding the end of the suction tube before attaching it to the suction catheter, as suggested by the AARC clinical practice guidelines. ${ }^{6}$ Meanwhile, a prepackaged disposable suction catheter kit that contains sterile gloves, a sterile suction catheter and a sterile saline solution could be an excellent choice to help avoid the contamination of saline container. However, to our knowledge, no such prepackaged suction catheter kits exist in China now, which needs to be developed and put into practice.

CSS can be a choice for Chinese patients admitted to emergency departments, when the cost-effectiveness, medical insurance categories, status of the individual patient and severity of disease were comprehensively considered. In this study, $63.72 \%$ of the nurses responded that their departments used OSS in clinical work, which is much lower than in Australia and New Zealand (86.6\%). ${ }^{19}$ Regarding the barriers to using CSS, the major problem was that CSS appeared to be more expensive than OSS. In terms of costs, Afshari $e t a t^{20}$ showed that the cost of CSS is lower than OSS for the patients who are admitted to the ICU for $>2$ days. In emergency departments equipped with emergency ICU wards, and for patients detained in the emergency department without access to be admitted to the inpatient department for further treatment, nurses can select CSS due to a preliminary assessment of the patient's length of stay in emergency department wards and total time in hospital. On the indications of using CSS, the AARC guidelines and the CNA group standards stressed that CSS is suggested for adults with high FiO2 or PEEP, or those at risk of lung derecruitment, haemodynamic instability, respiratory infection (eg, tuberculosis) and multidrug-resistant bacterial infection in the respiratory tract. ${ }^{6}{ }^{7}$ CSS should be systematically used to reduce the risk of cross-contamination in emergency departments during the COVID-19 pandemic. ${ }^{21}$ Meanwhile, Dastdadeh et $a l^{22}$ found that CSS reduced hand and equipment contamination during tracheal suctioning. OSS is only used once when ventilator is disconnected, whereas CSS can be used more than once and permits suction without disconnecting the ventilator. ${ }^{23}$ Ebrahimian $e t a l^{24}$ stated that compared with OSS, CSS can cause higher reductions in pain levels during and after suctioning in patients with head traumas, and can also cause higher improvements in physiological indicators, such as respiratory rate, O2 saturation and end-tidal CO2. Since patients admitted to emergency departments often have acute changes in vital signs, use of CSS could reduce the impact on the heart rate and arterial pressure.

Another important finding was that the scores of emergency department nurses regarding airway management attitude were low, the sputum aspiration practice scores and practice of VCBs scores were relatively optimistic. Meanwhile, significant differences were found according to age, experience, educational level, technical title, administrative post, training in airway management and a specialist in airway management. Bulbul et $a t^{25}$ suggested that the knowledge level of most of the nurses in adult ICUs in a teaching hospital in western Turkey was good and their practice levels were fair, and they were higher than those of this study. This might be explained by a higher ICU training experience of nurses in their studies, highlighting the need for regular training in emergency departments in China.

In general, nurses who are older and with longer years of nursing experience, higher educational level, higher technical title, and administrative post might have a better aptitude and richer experience in airway management practice than others. Factors such as age, years of nursing experience, educational levels, technical title and the administrative post can be considered external determinants. On the other hand, a lack of training and no specialisation in airway management can be changed by the proper training. A study by Mwakanyanga et $a l^{26}$ suggested that training, provision of clinical guidelines and adequate support to nurses can foster adherence to clinical practice guidelines. Nursing administrators and educators should provide nurses with regular training courses about airway management, and operation practice in clinical work should regularly be assessed by clinical supervisors. ${ }^{27}$ Pinto $e t a l^{28}$ also stated that necessary training and continuing education on guidelines are warranted and should improve nursing quality. Noticeably, positive correlations were observed among the three scores, indicating that with adequate knowledge of airway management, nurses' attitude will change as well as their behaviours in clinical airway management practice.

This study showed that lack of equipment and resources was the most important barrier to adherence to clinical practice guidelines. Jansson $e t a l^{29}$ confirmed that most of the obstacles toward applying evidence-based guidelines were beyond the control of individual nurses. On the other hand, evaluation and auscultating before the suction procedure, and performing interrupted continuous sedative infusions are factors that can be changed by nursing administrators and educators through regular training and practice. Similarly, in the study by Bulbul et $a l,{ }^{25}$ the proportion of nurses who performed auscultation before suctioning was very low. Therefore, as an objective method to understand the patients' need for aspiration, evaluation and auscultating should be stressed rather than nurses' experiences. Borkowska $e t a l^{30}$ found a considerable discrepancy between international recommendations and actual sedation practices. Standardisation of sedation practices across different institutions on the national level may improve the quality of care.

This study had several strengths. First, it surveyed a nationwide sample of Chinese nurses from 143 districts in 31 provinces in 7 administrative regions in China. Moreover, all the data were collected throughout the country within 3 months to ensure adequate responses. The results provide valuable evidence for nursing managers to develop strategies for improving airway management conditions, and help educators provide effective training for nurses. They also indicate a shortage of equipment 
and resources for airway management in emergency departments, which calls for more attention from the healthcare institutions and government, especially in the context of the COVID-19 pandemic.

Nevertheless, the study also has several limitations that must be acknowledged. First, this was a quantitative study in which all the data came from China, limiting the generalisability of this study. Due to the inability to track the survey distribution and the inaccessibility of hospitals' names, it is impossible to calculate a response rate and to determine whether the nurses were evenly distributed within a given district. Besides, data were collected via a self-designed questionnaire, and no standardised instrument was used. Other potential biases that may have affected this study include the reliance on participant self-reporting and recall bias.

\section{CONCLUSION}

This study comprehensively discussed the airway management equipment and clinical practice in emergency department wards in China and factors that influenced the nurses' airway management practice. It showed inadequate management of equipment and environment in OSS; Chinese emergency department managers need to pay more attention to monitoring saline containers and equipment surfaces for contamination, and identify better methods for assessing equipment availability. For the use of CSS, the major barrier was high cost; nurses can choose CSS when costs, status of the individual patient and severity of disease are comprehensively considered. Emergency department nurses' scores of airway management attitude, practice of sputum aspiration and practice of VCBs were affected by demographic and job-related characteristics. These factors should be considered to improve airway management quality by clinical nurses, managers and educators. Regular training in airway management should be encouraged. Equipment and resources for airway management in emergency departments should be guaranteed to improve airway management quality and optimise patient outcomes.

Acknowledgements The authors thank the Emergency Medicine Committee of the Chinese Nursing Association for its organisation and assistance in data collection.

Contributors HW and SH conceived and supervised the study, recruited collaborators for survey distribution and data collection. JD, SH, DZ and WL designed the questionnaire and assisted in data collection; JD and MH analysed data and wrote the manuscript. SH and JX made manuscript revisions. SH had full access to the data, controlled the decision to publish and accept full responsibility for the conduct of this study, as the guarantor. All authors reviewed the results and approved the final version of the manuscript.

Funding The authors have not declared a specific grant for this research from any funding agency in the public, commercial or not-for-profit sectors.

Competing interests None declared.

Patient consent for publication Not required.

Ethics approval This study involves human participants and was approved by the ethics committee of Tongji Hospital, Tongji Medical College, Huazhong University of Science and Technology (\#TJ-IRB20191228). Participants gave informed consent to participate in the study before taking part.
Provenance and peer review Not commissioned; externally peer reviewed.

Data availability statement Data are available upon reasonable request. Data are available upon reasonable request from the corresponding author (sfhuang2008@ 163.com). Due to the anonymous nature of the survey, it was not possible to disseminate the results of this study to the participants.

Supplemental material This content has been supplied by the author(s). It has not been vetted by BMJ Publishing Group Limited (BMJ) and may not have been peer-reviewed. Any opinions or recommendations discussed are solely those of the author(s) and are not endorsed by BMJ. BMJ disclaims all liability and responsibility arising from any reliance placed on the content. Where the content includes any translated material, BMJ does not warrant the accuracy and reliability of the translations (including but not limited to local regulations, clinical guidelines, terminology, drug names and drug dosages), and is not responsible for any error and/or omissions arising from translation and adaptation or otherwise.

Open access This is an open access article distributed in accordance with the Creative Commons Attribution Non Commercial (CC BY-NC 4.0) license, which permits others to distribute, remix, adapt, build upon this work non-commercially, and license their derivative works on different terms, provided the original work is properly cited, appropriate credit is given, any changes made indicated, and the use is non-commercial. See: http://creativecommons.org/licenses/by-nc/4.0/.

ORCID iD

Sufang Huang http://orcid.org/0000-0003-4071-8597

\section{REFERENCES}

1 Turner JS, Bucca AW, Propst SL, et al. Association of checklist use in endotracheal intubation with clinically important outcomes: a systematic review and meta-analysis. JAMA Netw Open 2020;3:e209278.

2 Scott JA, Heard SO, Zayaruzny M, et al. Airway management in critical illness: an update. Chest 2020;157:877-87.

3 Toolis M, Tiruvoipati R, Botha J, et al. A practice survey of airway management in Australian and New Zealand intensive care units. Crit Care Resusc 2019;21:139-47.

4 Marini AL, Khan R, Mundekkadan S. Multifaceted bundle interventions shown effective in reducing VAP rates in our multidisciplinary ICUs. BMJ Qual Improv Rep 2016;5:u205566. w2278.

5 Liu W, Yang Y, Jiao Y, et al. Evaluation of the effects of applying the ventricular care bundle (VCB) method for reducing ventilatorassociated pneumonia (VAP) in the intensive care unit of a general Chinese tertiary hospital. Ann Palliat Med 2020;9:2853-61.

6 American Association for Respiratory Care. AARC clinical practice guidelines. endotracheal suctioning of mechanically ventilated patients with artificial airways 2010. Respir Care 2010;55:758-64.

7 Chinese Nursing Association. Endotracheal suctioning in adults receiving invasive mechanical ventilation.[online]. Available: http:// www.cna-cast.org.cn/cnaWebcn/upFilesCenter/upload/file/ 20210209/1612868651897014930.pdf [Accessed 11 Sep 2021].

8 Guan X, Yang H, Li H. Airway secretion aspiration performed by nurses in adults with invasive mechanical ventilation. Chin $J$ Nurs 2020;55:922-7.

9 Leddy R, Wilkinson JM. Endotracheal suctioning practices of nurses and respiratory therapists: how well do they align with clinical practice guidelines? Can J Respir Ther 2015;51:60-4.

10 Klompas M, Branson R, Eichenwald EC, et al. Strategies to prevent ventilator-associated pneumonia in acute care hospitals: 2014 update. Infect Control Hosp Epidemiol 2014;35:915-36.

11 Rotstein C, Evans G, Born A, et al. Clinical practice guidelines for hospital-acquired pneumonia and ventilator-associated pneumonia in adults. Can J Infect Dis Med Microbiol 2008;19:19-53.

12 Kalil AC, Metersky ML, Klompas M, et al. Executive summary: management of adults with hospital-acquired and ventilatorassociated pneumonia: 2016 clinical practice guidelines by the infectious diseases Society of America and the American thoracic Society. Clin Infect Dis 2016;63:575-82.

13 Álvarez Lerma F, Sánchez García M, Lorente L, et al. Guidelines for the prevention of ventilator-associated pneumonia and their implementation. The Spanish "Zero-VAP" bundle. Med Intensiva 2014;38:226-36.

14 Speck K, Rawat N, Weiner NC, et al. A systematic approach for developing a ventilator-associated pneumonia prevention bundle. Am J Infect Control 2016;44:652-6.

15 Sen S, Johnston C, Greenhalgh D, et al. Ventilator-Associated pneumonia prevention bundle significantly reduces the risk of 
ventilator-associated pneumonia in critically ill burn patients. J Burn Care Res 2016;37:166-71.

16 (IHI) loHI. How-to guide: prevent ventilator-associated pneumonia. Cambridge: Institute of Healthcare Improvement (IHI), 2012.

17 Suqin X, Liu Y, Hongyan Y. Application of a self-designed aseptic sputum suction kit. Am J Nurs Sci 2014;29:52-3.

18 Tabaeian SM, Yazdannik A, Abbasi S. Compliance with the standards for prevention of ventilator-associated pneumonia by nurses in the intensive care units. Iran J Nurs Midwifery Res 2017;22:31-6.

19 Tan CSL, Harrold M, Hill K. Approaches and adjuncts used by physiotherapists when suctioning adult patients who are intubated and ventilated in intensive care units in Australia and New Zealand: a cross-sectional survey. Aust Crit Care 2017;30:307-13.

20 Afshari A, Safari M, Oshvandi K, et al. The effect of the open and closed system suctions on cardiopulmonary parameters: time and costs in patients under mechanical ventilation. Nurs Midwifery Stud 2014;3:e14097.

21 He M, Xiong J, Huang S, et al. Airborne precautions recommended in Wuhan, China for bedside fiberoptic bronchoscopy examination of patients with COVID-19. J Infect 2020;81:e75-7.

22 Dastdadeh R, Ebadi A, Vahedian-Azimi A. Comparison of the effect of open and closed endotracheal suctioning methods on pain and agitation in medical ICU patients: a clinical trial. Anesth Pain Med 2016;6:e38337.

23 Sole ML, Bennett M, Ashworth S. Clinical indicators for endotracheal suctioning in adult patients receiving mechanical ventilation. $\mathrm{Am} \mathrm{J}$ Crit Care 2015;24:318-24.
24 Ebrahimian A, Tourdeh M, Paknazar F, et al. The effect of the open and closed system Suctions on pain severity and physiological indicators in mechanically ventilated patients with traumatic brain injury: a randomised controlled trial. Turk $J$ Anaesthesiol Reanim 2020;48:202-7.

25 Bülbül Maras G, Kocaçal Güler E, Eșer İsmet, et al. Knowledge and practice of intensive care nurses for endotracheal suctioning in a teaching hospital in Western turkey. Intensive Crit Care Nurs 2017;39:45-54.

26 Mwakanyanga ET, Masika GM, Tarimo EAM. Intensive care nurses' knowledge and practice on endotracheal suctioning of the intubated patient: a quantitative cross-sectional observational study. PLoS One 2018;13:e0201743.

27 Gomarverdi S, Khatiban M, Bikmoradi A, et al. Effects of a multicomponent educational intervention on nurses' knowledge and adherence to standard precautions in intensive care units. $J$ Infect Prev 2019;20:83-90.

28 Pinto HJ, D'silva F, Sanil TS. Knowledge and practices of endotracheal suctioning amongst nursing professionals: a systematic review. Indian J Crit Care Med 2020;24:23-32.

29 Jansson MM, Syrjälä HP, Talman K, et al. Critical care nurses' knowledge of, adherence to, and barriers toward institution-specific ventilator bundle. Am J Infect Control 2018;46:1051-6.

30 Borkowska M, Labeau S, Schepens T, et al. Nurses' sedation practices during weaning of adults from mechanical ventilation in an intensive care unit. Am J Crit Care 2018;27:32-42. 